\title{
A study of role of colour Doppler in evaluation of abnormal uterine bleeding at medicine and gynecology departments at a tertiary care institute of central India
}

\author{
Somen Bhattacharjee ${ }^{1 *}$, Yogendra Jamra ${ }^{2}$, Shiv Shankar Sharma ${ }^{2}$, Neetu Dongre ${ }^{1}$ \\ ${ }^{1}$ Department of Obstetrics and Gynecology, ${ }^{2}$ Department of Medicine, Mahatma Gandhi Memorial Medical College, \\ Indore, India
}

Received: 14 March 2016

Revised: 23 March 2016

Accepted: 25 March 2016

*Correspondence:

Dr. Somen Bhattacharjee,

E-mail: drsomenmd@yahoo.com

Copyright: $\odot$ the author(s), publisher and licensee Medip Academy. This is an open-access article distributed under the terms of the Creative Commons Attribution Non-Commercial License, which permits unrestricted non-commercial use, distribution, and reproduction in any medium, provided the original work is properly cited.

\section{ABSTRACT}

Background: Abnormal uterine bleeding (AUB) at any age in women's life is disruptive and worrisome. The purpose of the study is to determine the effectiveness of color Doppler transvaginal ultrasonography (CDTU) in detection of intrauterine pathology in those patients with abnormal uterine bleeding.

Methods: The present study was conducted on 50 patients of AUB selected from Gynecology and Medicine OPD of M.G.M. Medical College and M.Y. and associated group of hospitals, Indore during the period of May 2012 to December 2012. All patients underwent D\&C (for endometrial biopsy) to evaluate ultrasonographic findings. Ultrasonographic variables considered were: endometrial thickness, gray-scale and color Doppler sonographic findings, resistance index and pulsatility index.

Results: CDTU showed abnormal studies in 11 patients (22\%) cases. Endometrial biopsy revealed abnormalities in 14 women. $91 \%$ of cases, which were having abnormal CDTU, had abnormal endometrium. $10 \%$ cases were missed by CDTU and were having abnormal HPR of which $67 \%$ had simple endometrial hyperplasia; rest 33\%-cystic glandular hyperplasia. In abnormal CDTU finding group, only $9 \%$ cases had normal HPR. Color doppler effectively diagnosed all the malignant and potentially malignant states.

Conclusions: CDTU can be used to as an effective tool in woman with evaluation of AUB after TVS has been performed for visualizing endometrium.

Keywords: AUB, CDTU, Histopathological report

\section{INTRODUCTION}

Abnormal uterine bleeding is one of the most common problems that challenge the gynaecologists. Virtually every woman will, at some point in her life, experience episodes of bleeding that can be perceived as abnormal. A correct diagnosis is essential because of the consequences of bleeding and the implications of the treatment.
Abnormal uterine bleeding (AUB) generally describes all abnormal patterns of bleeding that may result from a variety of causes, including anovulation, pregnancy, uterine pathology and coagulopathies. ${ }^{1}$

The prevalence of AUB is estimated to be 11-13\% in the general population and increases with age, ${ }^{2}$ significantly impacting quality of life and imposing financial burden. 
So, it is prudent that there should be a diagnostic tool which is safe, less or non-invasive, cheap, and simple with a quick result.

In the past, D\&C was considered as the gold standard to exclude endometrial pathology. This procedure has two main drawbacks: first, it is an invasive procedure and has to be done under suitable anaesthesia; second, it may miss lesions such as polyps or endometrial carcinoma in not less than $10 \%$ of cases. ${ }^{3}$

Hysteroscopy is another method that allows direct visualisation of the uterine cavity that can be used as an office technique in the evaluation of endometrial disorders. But due to its invasive nature, cost, limited use and lack of user skill, it cannot be made available everywhere, especially in economically burdened areas like ours.

Transvaginal sonography (TVS) is relatively cheap, needs no anaesthesia and being non-invasive, it can be the first diagnostic step in evaluation of AUB. ${ }^{4}$

In general, endometrial thickness of more than $8 \mathrm{~mm}$ is considered suspicious of endometrial pathology in perimenopausal women with AUB and further investigation is recommended..$^{5}$ Transvaginal route has greatly improved image resolution due to the proximity of probe to the endometrium. It effectively allows detection of abnormal endometrium as well as intracavitory lesions. ${ }^{6}$ Studies using transabdominal ultrasonography has shown that endometrial thickness measured correlated well with well with results obtained on histopathology. ${ }^{7}$

Power Doppler is based on the amplitude of the Doppler signal. It is insonation angle independent and is more sensitive to low-velocity blood flow. It facilitates the detection of flow, where present, depicting more clearly and reliably the vascular architecture.

\section{Aims and objectives}

- To study the role of colour Doppler in evaluation of abnormal uterine bleeding and its correlation with histopathology after dilatation and curettage.

- Colour and power Doppler sonography-a possible role in reducing the number of dilatation and curettage procedure.

- Evaluation of the role of colour Doppler sonography to discriminate between benign and malignant endometrial condition in women presenting with abnormal bleeding and thickened endometrium.

- To determine whether measurement of blood flow in endometrial and uterine vessels by colour Doppler sonography is valuable in the diagnosis of neoplastic endometrial pathology (hyperplasia and carcinoma) in women with abnormal bleeding.

\section{METHODS}

The present study was conducted on 50 patients selected from Gynecology and Medicine OPD of M.G.M. Medical College and M.Y. and associated group of hospitals, Indore during the period of May 2012 to December 2012.

\section{Study design}

It is prospective study; sensitivity and specificity values were calculated from 2 by 2 tables using SPSS (Statistical Package for the Social Sciences) version 20.

\section{Inclusion criteria}

Cases of excessive and or irregular bleeding per vaginum in the age group of 30 to 50 years were selected randomly.

\section{Exclusion criteria}

- Women with genital tract malignancy

- Carcinoma breast

- History of drug intake like tamoxifen

- Women with defined cervical/vaginal pathology

- Menopause

- Pregnancy

- Endocrine disorders like thyroid dysfunction; coagulation disorders

\section{Method}

All the selected patients were admitted. Complete history, including specific patterns of bleeding PV was taken. Each patient was subjected to a thorough medical checkup followed by a pelvic examination. Patients were then referred to radiology department for Doppler studies and the relevant findings were recorded. Finally, all the patients underwent dilatation and curettage; samples of endometrium were sent for histopathological examination, which is considered as the gold standard.

\section{Investigations}

Blood group, Rh typing, complete blood count, liver and renal function test, coagulation profile, blood sugar and thyroid function test were done.

\section{Special investigations}

- Color doppler transvaginal ultrasonography (CDTU).

- Endovaginal probe was equipped with colour and power Doppler capabilities. Endometrial thickness of $<8 \mathrm{~mm}$ was considered as normal and a thicker endometrium was classified as abnormal.

- Ultrasonographic variables considered were: endometrial thickness, gray-scale and color 
Doppler sonographic findings of endometrium and uterine vessels, resistance index and pulsatility index.

- Histopathological examination of specimens.

\section{RESULTS}

Maximum number of patients belonged to the age group of 36-45 years.

Table 1: Age wise distribution (in percentage).

\begin{tabular}{|lll|}
\hline Age group & No. of patients & Percentage \\
\hline $30-35$ & 10 & $20 \%$ \\
\hline $36-40$ & 14 & $28 \%$ \\
\hline $41-45$ & 14 & $28 \%$ \\
\hline $46-50$ & 12 & $24 \%$ \\
\hline
\end{tabular}

$72 \%$ cases had normal endometrium (50\%-secretory; $22 \%$-proliferative).

Table 2: Endometrial pattern.

\begin{tabular}{|lll|}
\hline Types & $\begin{array}{l}\text { No. of } \\
\text { Patients }\end{array}$ & Percentage \\
\hline Secretory & 25 & 50 \\
\hline Proliferative & 11 & 22 \\
\hline Simple hyperplasia & 5 & 10 \\
\hline Atypical hyperplasia & 1 & 2 \\
\hline $\begin{array}{l}\text { Atypical hyperplasia with } \\
\text { Ca in situ }\end{array}$ & 4 & 8 \\
\hline Cystic glandular hyperplasia & 3 & 6 \\
\hline Ca endometrium & 1 & 2 \\
\hline Total & 50 & 100 \\
\hline
\end{tabular}

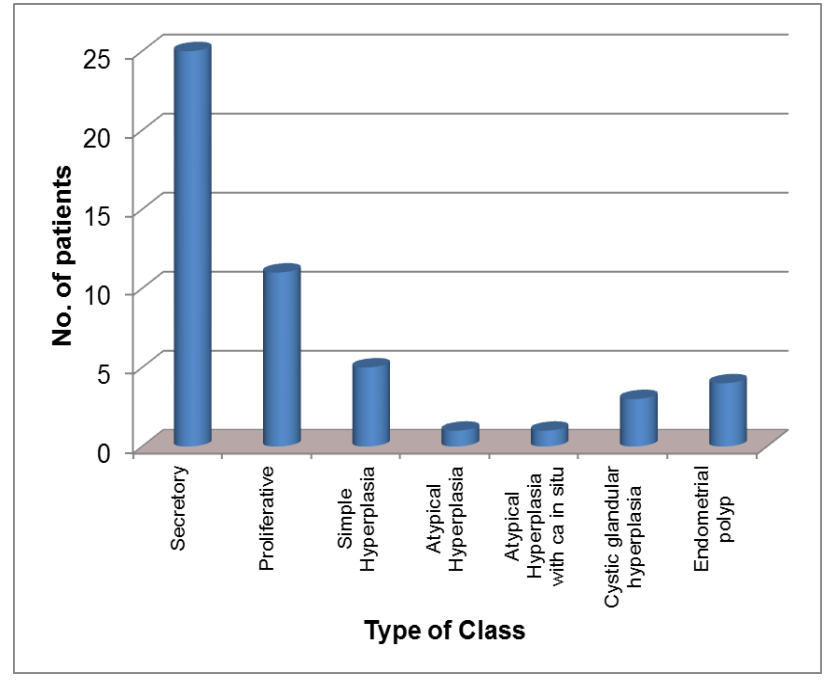

Figure 1: Histopathological findings.

Maximum no. of the patients $(64 \%)$ had healthy pelvic organs and rest patients had some associated pathologies.

Table 3: Associated pelvic findings.

\begin{tabular}{|lll|}
\hline Findings & No. of Cases & Percentage \\
\hline Healthy pelvic organ & 32 & 64 \\
\hline Cervical erosion & 11 & 22 \\
\hline $\begin{array}{l}\text { Uniform enlargement } \\
\text { of uterus } \\
\text { (Adenomyosis) }\end{array}$ & 5 & 10 \\
\hline Palpable ovaries & 2 & 4 \\
\hline Total & 50 & 100 \\
\hline
\end{tabular}

Maximum no patients presented with menorrhagia were having endometrium in secretory phase. The patient having carcinoma endometrium, presented with metropathia.

Table 4: Correlation between HPR and the patterns of menstrual symptoms.

\begin{tabular}{|c|c|c|c|c|}
\hline Type of endometrium & Menorrhagia & Menometrorrhagia & $\begin{array}{l}\text { Polymenorrhia/ } \\
\text { polymenorrhagia }\end{array}$ & Metropathia \\
\hline Secretory & $16(32 \%)$ & $6(12 \%)$ & $2(4 \%)$ & $1(2 \%)$ \\
\hline Proliferative & $6(12 \%)$ & $4(8 \%)$ & $1(2 \%)$ & \\
\hline Simple hyperplasia & $4(8 \%)$ & $1(2 \%)$ & & \\
\hline Atypical hyperplasia & $1(2 \%)$ & & & \\
\hline CIN & & $1(2 \%)$ & & $3(6 \%)$ \\
\hline Cytic glandular hyperplasia & & $1(2 \%)$ & & $2(4 \%)$ \\
\hline Carcinoma endometrium & & & & $1(2 \%)$ \\
\hline
\end{tabular}

In Abnormal color Doppler finding group, only 9\% cases had normal HPR. Color Doppler effectively diagnosed all the malignant and potentially malignant states.
In Normal colour Doppler finding group, 90\% cases are showing normal HPR. $10 \%$ cases were missed by CDTU and were having abnormal HPR of which $67 \%$ had simple endometrial hyperplasia; rest 33\%-cystic glandular hyperplasia. 
Table 5: Correlation between colour Doppler and HPR.

\begin{tabular}{|c|c|c|c|}
\hline Doppler finding & $\begin{array}{l}\text { No. of } \\
\text { Cases }\end{array}$ & HPR Finding & $\begin{array}{l}\text { No. of } \\
\text { Cases }\end{array}$ \\
\hline \multirow{2}{*}{$\begin{array}{l}\text { Normal colour } \\
\text { Doppler finding }\end{array}$} & \multirow{2}{*}{$\begin{array}{l}39 \\
(78 \%)\end{array}$} & $\begin{array}{l}\text { Normal HPR } \\
\text { finding }\end{array}$ & $\begin{array}{l}35 \\
(90 \%)\end{array}$ \\
\hline & & $\begin{array}{l}\text { Abnormal } \\
\text { HPR finding }\end{array}$ & $\begin{array}{l}4 \\
(10 \%)\end{array}$ \\
\hline \multirow{2}{*}{$\begin{array}{l}\text { Abnormal colour } \\
\text { Doppler finding }\end{array}$} & \multirow{2}{*}{$\begin{array}{l}11 \\
(22 \%)\end{array}$} & $\begin{array}{l}\text { Normal HPR } \\
\text { finding }\end{array}$ & $\begin{array}{l}1 \\
(9 \%)\end{array}$ \\
\hline & & $\begin{array}{l}\text { Abnormal } \\
\text { HPR finding }\end{array}$ & $\begin{array}{l}10 \\
(91 \%)\end{array}$ \\
\hline Total & 50 & & 50 \\
\hline
\end{tabular}

\section{DISCUSSION}

In this series maximum percentage of patients belong to the age group of 30-45 years age. The mean age of the patients was 44 as observed by Angela Pascual et al ${ }^{9}$ (Table 1).

In our study $72 \%$ of patient have normal endometrial pattern in histopathological report. In which $50 \%$ had secretory changes and $22 \%$ had proliferative changes. Rest $28 \%$ patient have abnormal endometrial pattern including simple endometrial hyperplasia (commonest), atypical hyperplasia, atypical hyperplasia with carcinoma insitu. Cystic glandular hyperplasia and carcinoma endometrium. In our study, $67 \%$ of the abnormal histopathological reports were simple hyperplasia.(Table2). This is in conscience, with the study of S Kayasthaet et $a l,{ }^{10}$ where the incidence of simple hyperplasia was $74.19 \%$. The overall incidence of carcinoma endometrium was $2 \%$ while Dangal et $\mathrm{al}^{11}$ reported it to be $7.1 \%$. The incidence of carcinoma endometrium was less in our study as we had excluded the post-menopausal patients.

In our study, $64 \%$ patients had healthy pelvic organs, and the rest had associated pathologies like cervical erosion, adenomyosis,palpable ovaries etc (Table 3). Shobha S. Pillai et al, ${ }^{12}$ reported maximum incidence of fibroid uterus $(55.7 \%)$ in her study, as an associated clinical finding.

On comparing the menstrual symptoms with the histopathological findings, our study shows maximum patients, having secretory phase endometrium (which was the most common histopathological finding), presented with menorrhagia (Table 4). In a similar study of Shobha S. Pillai et al, ${ }^{12}$ maximum patients had proliferative phase endometrium and presented with menorrhagia.

In the present study, $22 \%$ patients had abnormal colour Doppler. The major abnormalities detected in the colour Doppler studies were low RI and PI indices, dense vascularities and high endometrial volume (Table 5).
Aleem et $\mathrm{al}^{13}$ also found RI and PI were significantly less in the cases of endometrial hyperplasia. Alcazar et $\mathrm{al}^{14}$ in his study found that the endometrial volumes were significantly higher in malignant conditions.

\section{CONCLUSIONS}

Colour Doppler transvaginal ultrasonography (CDTU) of the endometrium has become an important part of the evaluation of women presenting AUB. It is fairly sensitive, specific, non-invasive, low-cost procedure with good patient acceptability. In patients with AUB, ultrasound-based triage has become widely accepted.

In our study, CDTU in evaluation of abnormal uterine bleeding is well correlated with histopathology after dilatation and curettage. So colour Doppler transvaginal ultrasonography would result in a significant reduction of endometrial biopsy or curettage.

The role of colour Doppler sonography to discriminate between benign and malignant endometrial condition in women presenting with abnormal bleeding and thickened endometrium is not conclusive because of small no of cases.

Although the results of Doppler were quite varied, it can be suggested as a screening tool for malignancy. It has a good role in supplementing the diagnosis after transvaginal ultrasonography has been performed for visualizing endometrium followed by endometrial biopsy.

\section{ACKNOWLEDGEMENTS}

The author wishes to record his deep sense of gratitude to the Head of the department of Obstetrics and Gynecology and the Dean, MGM Medical College, Indore, MP, for providing necessary facilities to carry out the research.

\section{Funding: No funding sources \\ Conflict of interest: None declared}

Ethical approval: The study was approved by the Institutional Ethics Committee

\section{REFERENCES}

1. Fritz M, Speroff L. Clinical gynaecologic endocrinology and infertility. Eighth edition. Lippincott Williams and Wilkins; 2010:592.

2. Marret H, Fauconnier A, Chabbert-Buffe N, Cravello L, Golfier F, Gondry J et al. Clinical practice guidelines on menorrhagia: management of abnormal uterine bleeding before menopause. Eur J Obstet Gynecol Reprod Biol. 2010;152(2):133-7.

3. Bakos $\mathrm{O}$, Heimer G. Transvaginal ultrasonographic evaluation of endometrium related to histological findings in pre-ad perimenopausal Women. Gynecol Obstet Invest. 1998;45:199-204.

4. Dijkhuizen FP, Brolmann HA, Potters AE, Bongers MY, Heinz AP. The accuracy of transvaginal 
ultrasonography in the Diagnosis of endometrial abnormalities. Obstet Gynecol. 1996;87:345-9.

5. Spandorfer SD, Arrendondo-Soberon F, Loret de Mola JR, Feringbang RF. Reliability of intraobserver and intraobserver sonographic endometrial stripe thickness measurements. Fertil Steril. 1998;70:152-4.

6. Smith Brindman R, Kerlikowske K, Felstein VA, Subak L, Scheidler J, Segal M et al. Endovaginal ultrasound to exclude Endometrial cancer and other endometrial abnormalities. JAMA. 1998;280:1510-7.

7. Fleischer AC, Kalemeris GC, Machin JE, Entman SS, James AE Jr. Sonographic depiction of normal and abnormal Endometrium with histopathologic correlation. J Ultrasound Med. 1986;5:445-52.

8. Alcazar JL, Castillo G, Minguez JA, Galan MJ. Endometrial blood flow mapping using transvaginal power Doppler sonography In women with postmenopausal bleeding and thickened Endometrium. Ultrasound Obstet Gynecol. 2003;21:583-8.

9. Pascual A, Graupera B, Tresserra F, Ubeda A, Hereter L, Rodriguez I et al. Color Doppler transvaginal ultrasound for detecting intrauterine disorders in patients with abnormal uterine bleeding; Gynaecol Perinatol. 2005;14(4):157-60.
10. S Kayastha. Study of endometrial tissue in dysfunctional uterine bleeding. Nepal Med Coll J. 2013;15(1):27-30.

11. Dangal G. A study of endometrium of patient with abnormal uterine bleeding at Chitwan valley. Kathmandu Univ Med J. 2003;1:110-2.

12. Pillai SS. Sonographic and histopathological correlation and evaluation of endometrium in perimenopausal women with abnormal uterine bleeding. Intern J Reprod Contracep Obstetr Gynecol. 2014;3(1):113-7.

13. Aleem F, Predanic M, Calame R, Moukhtar M, Pennisi J. Transvaginal color and pulsed Doppler sonography of the endometrium: a possible role in reducing the number of dilatation and curettage procedures. J Ultrasound Med. 1995;14:139-45.

14. Alcazar JL, Galvan R. Three-dimensional power Doppler ultrasound scanning for the prediction of endometrial cancer in women with postmenopausal bleeding and thickened endometrium. Am J Obstet Gynecol. 2009;200(1):44.e1-6.

Cite this article as: Bhattacharjee S, Jamra Y, Sharma S, Dongre N. A study of role of colour doppler in evaluation of abnormal uterine bleeding at medicine and gynecology departments at a tertiary care institute of central India. Int J Reprod Contracept Obstet Gynecol 2016;5:989-93. 